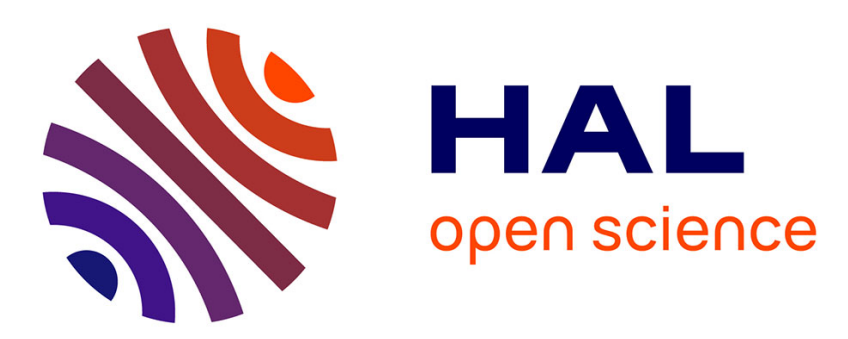

\title{
On the influence of fuel sulfur induced stable negative ion formation on the total concentration of ions emitted by an aircraft gas turbine engine: comparison of model and experiment
}

\author{
A. Sorokin, F. Arnold, P. Mirabel
}

\section{To cite this version:}

A. Sorokin, F. Arnold, P. Mirabel. On the influence of fuel sulfur induced stable negative ion formation on the total concentration of ions emitted by an aircraft gas turbine engine: comparison of model and experiment. Atmospheric Chemistry and Physics Discussions, 2003, 3 (6), pp.6001-6018. hal00327902

\section{HAL Id: hal-00327902 \\ https://hal.science/hal-00327902}

Submitted on 26 Nov 2003

HAL is a multi-disciplinary open access archive for the deposit and dissemination of scientific research documents, whether they are published or not. The documents may come from teaching and research institutions in France or abroad, or from public or private research centers.
L'archive ouverte pluridisciplinaire HAL, est destinée au dépôt et à la diffusion de documents scientifiques de niveau recherche, publiés ou non, émanant des établissements d'enseignement et de recherche français ou étrangers, des laboratoires publics ou privés. 


\section{On the influence of fuel sulfur induced} stable negative ion formation on the total concentration of ions emitted by an aircraft gas turbine engine: comparison of model and experiment

\section{A. Sorokin ${ }^{1,2,{ }^{*} \text {, F. Arnold }}{ }^{1}$, and P. Mirabel ${ }^{2}$}

${ }^{1}$ Atmospheric Physics Division, MPIK, P.O. Box 103980, D-69029 Heidelberg, Germany

${ }^{2}$ CGS of the Université Louis Pasteur and CNRS 1, rue Blessig, F-67084 Strasbourg, France

*Permanent address: IVTAN of the RAN 17a, Krasnokazarmennaya st., 111250 Moscow,

Russia

Received: 7 October 2003 - Accepted: 13 November 2003 - Published: 26 November 2003

Correspondence to: A. Sorokin (andrey.sorokin@mpi-hd.mpg.de)

Influence of fuel

sulfur induced stable negative ion formation

A. Sorokin et al.

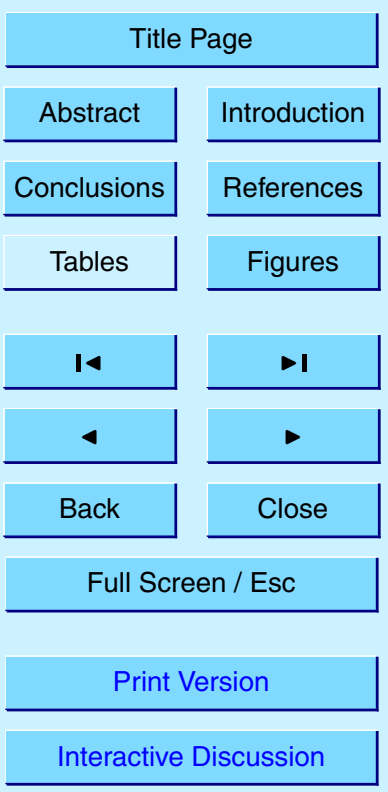




\section{Abstract}

A model which considers the formation and evolution of combustion ions in a combustor of an aircraft engine in dependence on the electron detachment efficiency from negative ions is presented. It is a further development of the model reported by (Sorokin

5 et al., 2003). The model allows to consider the effect of the transformation of primary negative ions to more stable secondary negative ions with a much higher electron affinity and as a consequence a greater stability with respect to electron thermal detachment. The formed stable negative ions most probably are sulfur-bearing ions. This effect slows down the charged particle neutralization rate leading to an increase of the concentration of positive and negative ions at the combustor exit. The results of the simulation and their comparison with the ground-based experimental data obtained within the framework of the project PartEmis (Particle emission, measurements and predictions of emission of aerosols and gaseous precursors from gas turbine engines; coordinator: C. Wilson) at the QinetiQ test facility at Pyestock, UK (Wilson et al., 2003) support the above hypothesis, i.e. the increase of the fuel sulfur content leads to an increase of the ion concentration at the combustor exit.

\section{Introduction}

Gaseous ions emitted by aircraft gas-turbine engines are of considerable interest as they may promote the formation of aerosols, contrails and perhaps even of clouds (Frenzel et al., 1994; Yu and Turco, 1998; Arnold et al., 1998 and 2000; Sorokin and Mirabel, 2001). Recently gaseous positive and negative ions have been measured in the exhaust of an aircraft engine just after the exit of the combustor in a test rig at the ground (Wilson et al., 2003; Haverkamp et al., 2003). These measurements prompted an interesting finding, namely an influence of the fuel sulfur content (FSC) on the total concentrations of positive $\left(n_{P}\right)$ and negative $\left(n_{N}\right)$ ions and this influence was found to vary with the fuel flow (FF) into the combustor. It was hypothesized by the authors of
ACPD

$3,6001-6018,2003$

Influence of fuel sulfur induced stable negative ion formation

A. Sorokin et al.

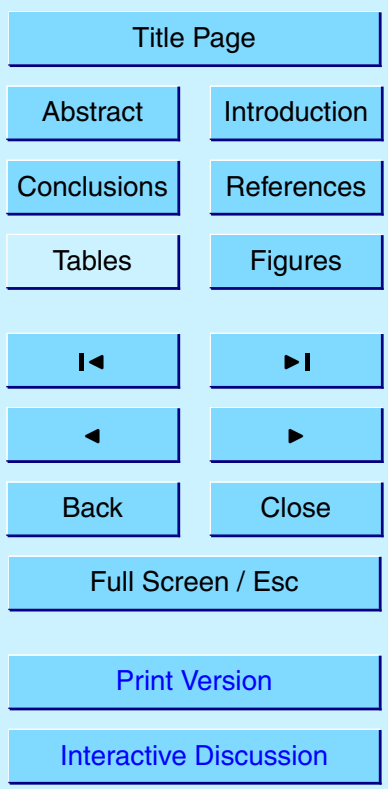

(C) EGU 2003 
this work, that at high FSC sulfur-bearing negative ions rapidly form and these ions have a rather high stability with respect to electron thermal and associative electron detachment, even at the high temperatures encountered in the combustor. Thereby the concentration of free electrons decreases and that effect slows down the neutralisation 5 rate of charged particles leading to an increase of $n_{P}$ and $n_{N}$. The present paper investigates that hypothesis by a theoretical model which considers the formation of charged particles in the combustor. The results of the model calculations support the above hypothesis.

\section{Model}

10 The model used for the present investigation builds on the model recently developed by Sorokin et al. (2003), but has the following modifications: (i) transformation of the primary negative ions $\mathrm{O}_{2}^{-}$to secondary negative ions $\mathrm{X}^{-}$is introduced; (ii) all $\mathrm{X}^{-}$ion species are lumped together and are assumed to experience electron detachment by a thermal or an associative mechanism which is slower than for $\mathrm{O}_{2}^{-}$; (iii) the rate of 15 electron detachment from $\mathrm{X}^{-}$relative to the rate of electron detachment from $\mathrm{O}_{2}^{-}$is introduced explicitly as an adjustable parameter $f_{d e t}$ in order to simulate the fuel sulphurinduced build-up of stable sulphur bearing negative ions.

For a high fuel sulfur content (HFSC) such as the one used in the PARTEMIS project experiments (Wilson et al., 2003) i.e. $1270 \mathrm{mg}$ of $S$ per $\mathrm{kg}$ of fuel (i.e. $1270 \mathrm{ppmm}$ ), 20 the expected concentration of $\mathrm{SO}_{2}$ molecules is about of $1.6 \times 10^{15} \mathrm{~cm}^{-3}$. This leads to a sufficiently rapid conversion of $\mathrm{O}_{2}^{-}$ions to $\mathrm{SO}_{2}^{-}$ions via electron transfer from $\mathrm{O}_{2}^{-}$ to $\mathrm{SO}_{2}$ since the electron affinities (EA) of neutral $\mathrm{O}_{2}$ and $\mathrm{SO}_{2}$ molecules are 0.45 and $1.11 \mathrm{eV}$, respectively, and the rate coefficient is close to the upper collision rate coefficient, i.e. $1 \times 10^{-9} \mathrm{~cm}^{3} \mathrm{~s}^{-1}$ at $T=1500-2000 \mathrm{~K}$. The mean $\mathrm{O}_{2}^{-}$lifetime with respect 25 to reaction with $\mathrm{SO}_{2}$ is hence around $10^{-6} \mathrm{~s}$. In comparison the $\mathrm{O}_{2}^{-}$lifetime with respect to thermal electron detachment is about of $1 \times 10^{-8} \mathrm{~s}$ for $T=1500-2000 \mathrm{~K}$ (Möhler et
ACPD

3, 6001-6018, 2003

\section{Influence of fuel}

sulfur induced stable negative ion formation

A. Sorokin et al.

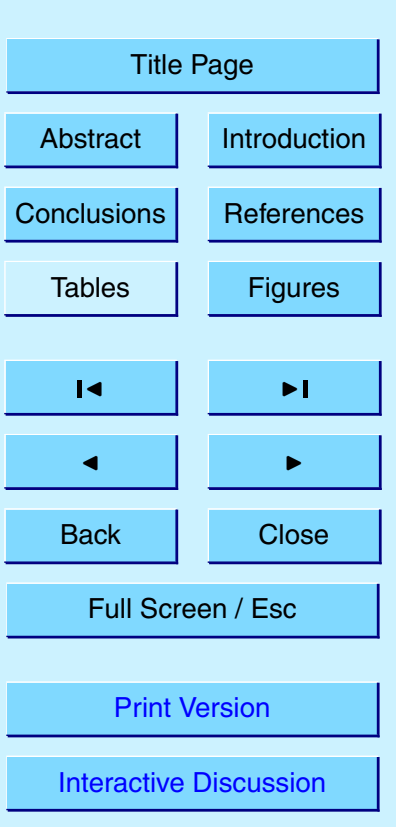

(C) EGU 2003 
al., 1992) and therefore electrons and $\mathrm{O}_{2}^{-}$are in a quasi-equilibrium. In addition, in the exhaust flow, a substantial fraction of the $\mathrm{O}_{2}^{-}$ions may experience conversion to the more stable sulfur ions. In fact the typical residence times of the combustion products in a post-flame zone (of about $5 \mathrm{~ms}$ ) and in the post-combustor zone (of about 5-10 ms) 5 is much longer than the time needed for these reactions to occur.

The $\mathrm{SO}_{2}^{-}$may further react with $\mathrm{SO}_{3}$ via electron transfer as $\mathrm{EA}\left(\mathrm{SO}_{3}\right)=2.06 \mathrm{eV}$ leading to $\mathrm{SO}_{3}^{-}$which in turn rapidly reacts with $\mathrm{SO}_{2}$ and $\mathrm{O}_{2}$ resulting in $\mathrm{SO}_{4}^{-}$and $\mathrm{SO}_{5}^{-}$ion formation (Möhler et al., 1992). These ions are more stable with respect to electron detachment as they have a much larger electron bond energy $(E A=5.1 \mathrm{eV})$. Building on recent gaseous sulfur (VI) measurements (Katragkou et al., 2003) in the exhaust of an aircraft gas-turbine engine at the combustor exit, a concentration of $\mathrm{SO}_{3}$ of about $(2-5) \times 10^{13} \mathrm{~cm}^{-3}$ is expected. This leads to an $\mathrm{SO}_{2}^{-}$lifetime of about $5 \times 10^{-5} \mathrm{~s}$ with respect to the reaction with $\mathrm{SO}_{3}$. The lifetime of $\mathrm{SO}_{3}^{-}$with respect to the reaction with $\mathrm{O}_{2}$ leading to the formation of $\mathrm{SO}_{5}^{-}$is much shorter $\left(\approx 10^{-9} \mathrm{~s}\right)$ because of the high con15 centration of oxygen molecules in the post-flame zone $\left(\mathrm{O}_{2} \sim 5 \times 10^{18} \mathrm{~cm}^{-3}\right)$. This last calculation is based on a rate constant $k=2.5 \times 10^{-10} \mathrm{~cm}^{3} \mathrm{~s}^{-1}$ (Möhler et al., 1992) and a temperature dependence proportional to $T^{-1 / 2}$. Thus the build-up of negative ions which resist electron detachment much better than $\mathrm{O}_{2}^{-}$is fast compared to the average residence time of combustion products in the post-flame zone of the combustor. The 20 effect of a partial conversion of primary negative oxygen ions to secondary sulphurbearing ions (such as $\mathrm{SO}_{3}^{-}, \mathrm{SO}_{4}^{-}$or $\mathrm{HSO}_{4}^{-}, \mathrm{SO}_{5}^{-}$) will be important for the concentration of free electrons only if the concentration of these secondary ions is comparable with the "initial" concentration of combustion ions formed in the flame zone.

The concentration of primary combustion ions depends on their formation rate $Q$ in 25 the flame zone and particularly in the flame front (Fialkov, 1997; Sorokin et al., 2003) which in turn depends on the fuel flow (FF) in the combustor (Lefebvre, 1985). Therefore, it is reasonable to assume that $Q$ directly depends on the fuel flow (FF) into the combustor. As a consequence for low FF (LFF), when the intensity of the formation

ACPD

3, 6001-6018, 2003

\section{Influence of fuel sulfur induced stable negative ion formation}

A. Sorokin et al.

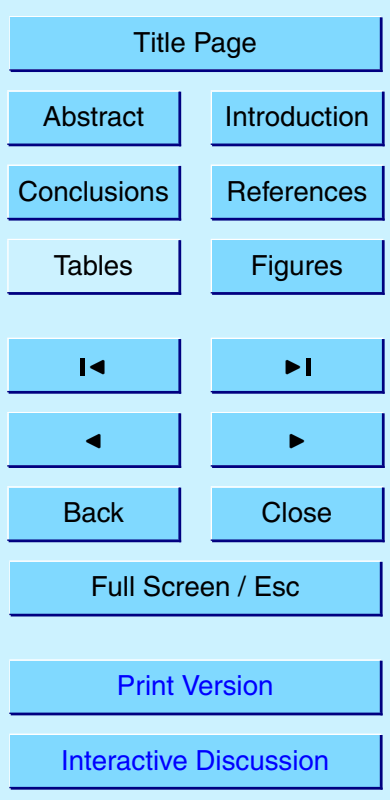

(C) EGU 2003 
of primary combustion ions is lower than for high FF, stable sulfur-ion formation may have an effect on the concentrations of free electrons and ions. More free electrons may lead to a higher rate of electron-ion recombination and hence to a lower exit concentration of combustion ions if, of course, there is no other more effective process 5 of electron interaction (e.g. soot particles). By contrast for high FF (HFF), due to the very high concentration of primary negative ions, it is possible that the conversion of $\mathrm{O}_{2}^{-}$ions to sulfur ions will have no effect on electrons and $\mathrm{O}_{2}^{-}$concentrations. In this case, it is expected that the variation of FSC will not influence the total emission of chemiions. Unfortunately, there exist considerable uncertainties concerning the de10 tailed mechanism of the evolution of negative ions in the combustor. Therefore, the present model does not attempt to treat in all details the complex interactions between neutral and charged species. Rather the model considers the relative efficiency $f_{d e t}$ of the electron detachment process from all possible $X^{-}$ions as a free input parameter. This parameter which can be varied between 1 to 0 reflects two possible limiting 15 cases (i) $f_{d e t}=1$ means the absence of $\mathrm{O}_{2}^{-}$conversion into secondary more stable negative ions (in this case, no effect of FSC on ion concentrations is expected), (ii) $f_{d e t}=0$ means that $\mathrm{O}_{2}^{-}$is fully converted into $\mathrm{X}^{-}$ions. The aim of the present study is therefore to investigate the influence of $f_{d e t}$ on the concentration of free electrons $\left(n_{e}\right)$, positive $\left(n_{P}\right)$ and negative $\left(n_{N}\right)$ ions in the combustor. The equations and reaction coefficients 20 used are described in detail in a recent paper by Sorokin et al. (2003). The model consists of a system of coupled differential equations, which describe the time evolution of the concentrations of electrons, negative and positive ion and also multi-charged soot particles. These equations describe the following processes: the chemiionization rate $Q(t)$ for the production of primary electrons and positive ions in the combustion zones; the soot-particle charging (multi-charged particles are allowed) due to both electron thermo-emission or electron and ion attachment to soot particles; the electron-ion and ion-ion recombination; electron attachment to and detachment from neutral molecules. Furthermore, we consider mono-dispersed soot particles $\left(r_{s}=20 \mathrm{~nm}\right)$, and the effect of soot oxidation in the combustion and dilution zones as well as soot-particle coagulation
ACPD

3, 6001-6018, 2003

\section{Influence of fuel sulfur induced stable negative ion formation}

A. Sorokin et al.

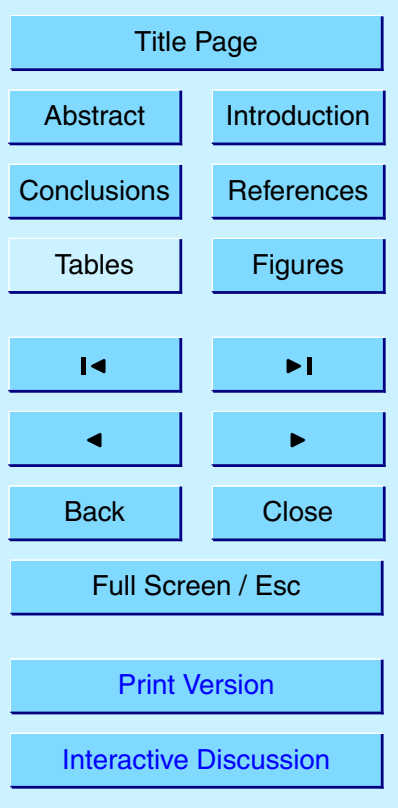

(C) EGU 2003 
are neglected. For all calculations, the soot-particle concentration was assumed to be $n_{s}=2 \times 10^{7} \mathrm{~cm}^{-3}$. The corresponding soot emission indexes $E I_{N}=2 \times 10^{14}$ particles and $E I_{S}=0.03 \mathrm{~g}$ soot per $\mathrm{kg}$ fuel are consistent with the measured values at the aircraft engine exit (Petzold et al., 1999). Finally, the work function for electron thermal emission 5 from soot surfaces was taken as $5 \mathrm{eV}$ in agreement with recent measurements made on combustion carbon particles (Matter et al., 1995).

\section{Results}

Figures $1 \mathrm{a}-\mathrm{c}$ show for three values of $f_{d e t}=0.001,0.01$ and 0.1 (neither $f_{d e t}=0$ or 1 will be achieved in a real case) and for $Q=2 \times 10^{14} \mathrm{~cm}^{-3} \mathrm{~s}^{-1}$ the concentration of free electrons $n_{e}$, positive $n_{P}$ and negative ions $n_{N}$ as a function of time in the combustor where the residence time is $\tau_{c}=5 \mathrm{~ms}$. It can be seen from these figures that $n_{e}$ initially increases steeply reaching its maximum values at about $t=1-2 \mu \mathrm{s}$. After $t=2 \mu \mathrm{s}$ the concentration of electrons decreases which reflects the attachment of electrons to oxygen molecules. The decrease of $n_{e}$ is of course more pronounced for the smaller $f_{d e t}$, 15 i.e. when for example $\mathrm{O}_{2}^{-}$ions are fully converted into $\mathrm{X}^{-}$ions with a high EA. Comparing Figs. $1 \mathrm{a}$ and $1 \mathrm{c}, n_{e}$ is seen to increase from $5 \times 10^{4}$ to $1.3 \times 10^{6} \mathrm{~cm}^{-3}$ at $t=5 \mathrm{~ms}$ when $f_{d e t}$ varies from $10^{-3}$ to $10^{-1}$.

Negative-ion formation becomes appreciable after $t=1 \mu \mathrm{s}$. Their concentration then increases very steeply, due to the attachment of electrons to $\mathrm{O}_{2}$ molecules until it reaches a maximum at about $0.2--0.4 \mathrm{~ms}$. The negative-ion concentrations $n_{N}$ are seen to vary with $f_{d e t}$, i.e. they go down from $2 \times 10^{8}$ to $4 \times 10^{7}$ at $t=5 \mathrm{~ms}$ when $f_{d e t}$ increases from $10^{-3}$ to $10^{-1}$, and this reflects the effect of electron detachment. The concentration of positive ions $n_{P}$ in the combustor exhibits less variations with $f_{d e t}$ but we still see a slight decrease of $n_{P}$ when $f_{\text {det }}$ varies from $10^{-3}$ to $10^{-1}$. This reflects 25 the fact that, as $f_{d e t}$ increases, more free electrons are available for recombination with positive ions. Since the electron-ion recombination coefficient $\alpha_{E P}$ exceeds markedly
ACPD

3, 6001-6018, 2003

Influence of fuel

sulfur induced stable negative ion formation

A. Sorokin et al.

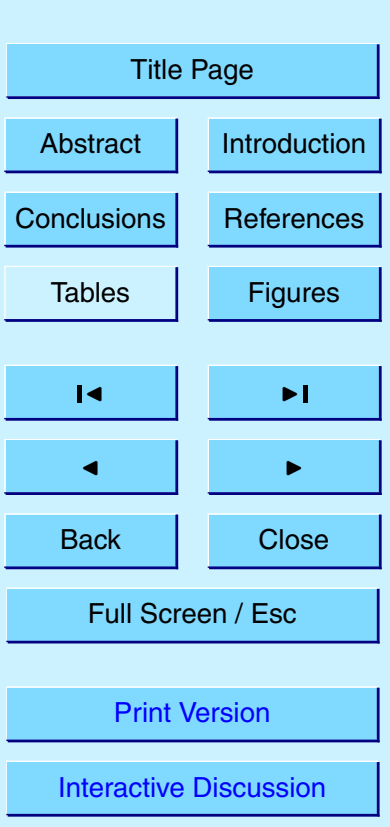

(c) EGU 2003 
the ion-ion recombination coefficient $\alpha_{i i}$ more positive ions are neutralized as $f_{d e t}$ increases.

These figures show that $n_{N}$ and $n_{P}$ do not change much after $t=20 \mu \mathrm{s}$. This shows that ion losses by electron-ion or ion-ion recombination and ion attachment to soot 5 particles are not very efficient after this time. For example, for $n_{N} \sim n_{P}=2 \times 10^{8} \mathrm{~cm}^{-3}$, $\alpha_{P N} \sim 5 \times 10^{-8} \mathrm{~cm}^{3} / \mathrm{s}$, and $T$ in the range $1500-2000 \mathrm{~K}$, the time scale of the ionion recombination process is about of $0.5 \mathrm{~s}$ which markedly exceeds the time span $\left(\tau_{c}=0.005 \mathrm{~s}\right)$ of ions in the combustor. Finally, in Figs. 1a-c are indicated the experimentally determined ion concentrations at the exit of a combustor obtained during 10 the PARTEMIS campaign. The indications HFSC and LFSC correspond to fuel sulfur contents of 1270 and 50 ppmm, respectively. For HFF this concentration is close to $2 \times 10^{8} \mathrm{~cm}^{-3}$.

Figures 2a-b show the variation of the ratios $n_{N} / n_{N 0}$ and $n_{P} / n_{P 0}$ with $f_{d e t}$ at the combustor exit ( $n_{N 0}$ and $n_{P 0}$ are the concentrations corresponding to the fixed value $15 f_{d e t}=0.02$, which represents the limit after which the curves merge) for three values of the primary chemiion formation rate $Q=10^{14}, 2 \times 10^{14}$ and $10^{15} \mathrm{~cm}^{-3} \mathrm{~s}^{-1}$. For the negative ions, one can see that as $f_{d e t}$ increases, $n_{N} / n_{N 0}$ decreases significantly and that this decrease is more pronounced for smaller values of $Q$. By contrast with negative ions, positive-ion concentrations are hardly influenced by $Q$ or $f_{\text {det }}$. If $Q$ is sufficiently 20 large $\left(Q>10^{14} \mathrm{~cm}^{-3} \mathrm{~s}^{-1}\right)$ their evolution in the combustor depends mainly on ion-ion recombination. However, for smaller values of $Q$ the concentration of negative ions is not large enough to lead to substantial depletion by ion-ion recombination and therefore the concentration of positive ions remains approximately constant in the combustor. In addition, for high enough values of $Q\left(>10^{14} \mathrm{~cm}^{-3} \mathrm{~s}^{-1}\right)$ the exit concentrations of positive and negative ions are approximately equal (Sorokin et al., 2003).

Figure 3 shows the variation of the exit ratios $n_{P}(f=0) / n_{P}(f=0.02)$ and $n_{N}(f=0) / n_{N}(f=0.02)$ as a function of $Q$. For positive ions this ratio remains approximately constant in spite of the variation of $Q$ over 6 orders of magnitude. The situation for negative ions is quite different. For small values of $Q$ the decrease of the electron de-

ACPD

$3,6001-6018,2003$

\section{Influence of fuel sulfur induced stable negative ion formation}

A. Sorokin et al.

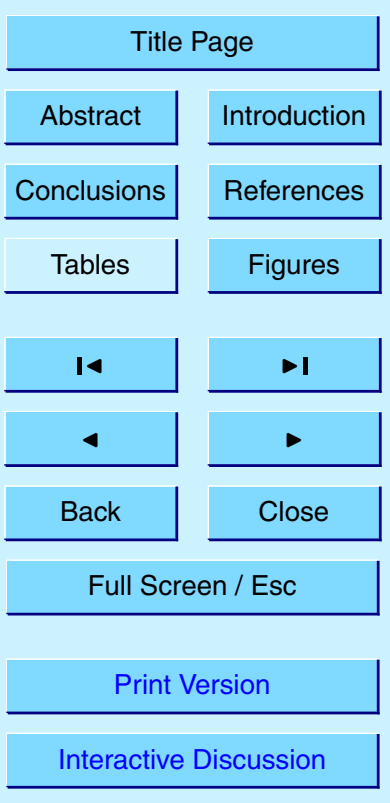

(C) EGU 2003 
tachment rate (to the limit $f_{d e t}=0$ ) leads to a marked increase of the exit concentration as compared to $f_{d e t}=0.02$. Such an influence of $Q$ and $f_{d e t}$ on the exit concentration of negative ions is directly connected to the predominance of the electron attachment processes leading to the formation of negative ions, over their depletion by ion-ion re5 combination. Smaller $f_{d e t}$ lead to larger $n_{N}$ behind the flame zone and larger exit $n_{N}$. Of course, increasing $Q$ leads to a stronger influence of ion-ion recombination and hence to a weaker dependence of the exit concentrations on $f_{d e t}$. In Fig. 3 are also indicated the experimental values (Haverkamp et al., 2003) of the ratio $\left(n_{N}\right)_{\mathrm{HFSC}} /\left(n_{N}\right)_{\mathrm{LFSC}}$ for the LFF and HFF cases. For HFF this ratio is close to unity while for LFF it is close to 1.5. 10 It follows from Fig. 3 that there exists a small range of $Q$ values $\left(10^{14}-10^{15}\right)$ for which the model is consistent with the measurements. For larger $Q$ there is no dependence on $f_{d e t}$ and for smaller $Q$ this dependence is too strong. Also for small values of $Q$ the simulated exit concentrations (e.g. $n_{P}=10^{7}$ and $n_{N}=8 \times 10^{7} \mathrm{~cm}^{-3}$ for $Q=10^{13} \mathrm{~cm}^{-3} \mathrm{~s}^{-1}$ and $\left.f_{d e t}=0\right)$ are lower than the corresponding measurements $\left(\approx 2 \times 10^{8} \mathrm{~cm}^{-3}\right.$ for both 5 positive and negative ions).

Figure 4 shows, for $Q=2 \times 10^{14}$, the variation of $n_{N}$ and $n_{P}$ with $f_{d e t}$ at the combustor exit. It can be seen that both concentrations are only slightly affected by the variation of $f_{d e t}$ (less than a factor of two) and that this variation is even less pronounced for positive ions. This behavior mostly reflects the stabilizing effect of the ion-ion recombination.

20 Thus the performed simulation shows that the model presented is able to predict experimental exit concentrations of positive and negative ions and to explain the observed trend in these concentrations with variation of FSC for different FF into the combustor. However, the model also predicts that the simulated result depends on some input parameters which are not well known (e.g. $Q$ and $f_{d e t}$ ). So together with the measurement example, simulations show that for very low values of $f_{\text {det }}(\approx 0)$ the exit concentration of free electrons is very small $\left(<10^{-4} \mathrm{~cm}^{-3}\right)$ However, already for $f_{d e t}=0.001$ the exit electron concentration is $n_{e} \geq 10^{4} \mathrm{~cm}^{-3}$. The later value probably can be measured. Also, the simulation yielded the expected result that the exit fractions of positively and

ACPD

3, 6001-6018, 2003

\section{Influence of fuel sulfur induced stable negative ion formation}

A. Sorokin et al.

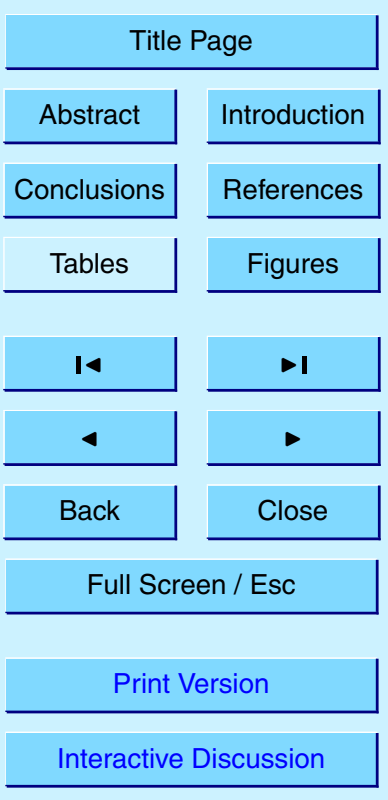

(C) EGU 2003 
negatively charged soot particles are in some dependence on the parameters $Q$ and $f_{d e t}$ and also depend on electron and ion concentrations. So it would be desirable to further investigate the interaction between electrons and ions and soot particles by simultaneous measurements of both ion and charged soot-particle exit concentrations.

5 However, in the given model, we consider only large soot particles and do not take into account the possible formation of charged and soot particles directly via the chemiionization mechanism. In general, the charging of smallest primary soot particles should influence the soot-particle aggregation process due to a change of the effective coagulation rate coefficient.

\section{Conclusions}

A numerical model has been developed to consider the effect of the formation of stable negative ions with high electron bond energy on the concentration of positive and negative ions at the combustor exit of an aircraft gas-turbine engine. The model includes the formation of primary electrons and positive ions by chemiionization, electron attach15 ment and detachment to neutral gas species, the ion-ion recombination, the interaction of electrons and ions, and the electron thermo-emission from the hot soot surfaces and the removal of charged species by soot particles in the combustor. Results of the simulation are compared with data obtained by MPI-K Heidelberg in the framework of the PartEmis project.

20 The comparison has shown that the formation of secondary stable negative ions such as $\mathrm{SO}_{\mathrm{x}}^{-}(\mathrm{x}=3-5)$ and as a consequence the induced decrease of the overall electron detachment coefficient, may lead to an increase of the concentration of ions at the combustor exit. This effect is most pronounced for a not too high chemiionization rate in the flame zone of the combustor. Both these results are confirmed by observations, i.e. the increase of the measured concentration of ions at the exit of the combustor with increasing FSC (fuel sulfur content) for low fuel flow into the combustor and a comparatively essentially smaller effect for high fuel flow. The performed simulation
ACPD

$3,6001-6018,2003$

Influence of fuel sulfur induced stable negative ion formation

A. Sorokin et al.

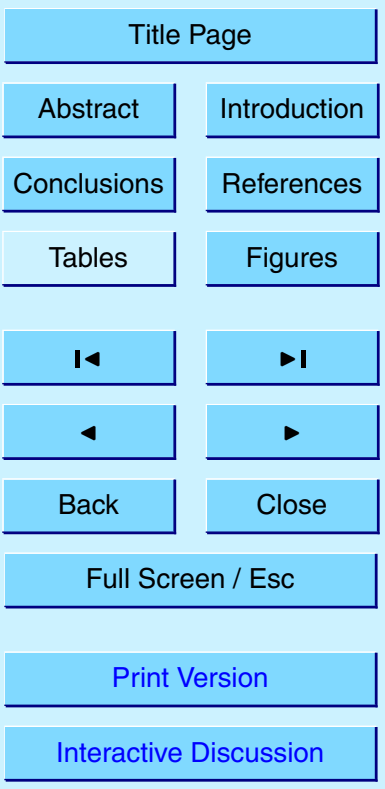

(C) EGU 2003 
and comparison with measurements have shown that the emission of combustion ions really may strongly depend on the sulfur chemistry and sulfur-bearing ion formation. This process should be also important for the charging of mainly smallest primary soot particles in the combustor.

5 Acknowledgements. Support of this work by the European Community through the contract G4RD-CT-2000-00207 (PARTEMIS) and by the INTAS project OPEN 2000-460 and by the Max Planck Society is gratefully acknowledged.

\section{References}

Arnold, F., Wohlfrom, K. H., Klemm, M. W., Schneider, J., Gollinger, K., Schumann, U., and Busen, R.: First gaseous ion composition measurements in the exhaust plume of a jet aircraft in flight: Implication for gaseous sulfuric acid, aerosols, and chemiions, Geophys. Res. Lett., 25, 2137-2140, 1998.

Arnold, F., Kiendler, A., Wiedemer, V., Aberle, S., Stilp, T., and Busen, R.: Chemiion concentration measurements in jet engine exhaust at the ground: Implications for ion chemistry and

Fialkov, A. B.: Investigation on ions in flames, Progress in Energy and Combustion Sciences, 23, 399-528, 1997.

Frenzel, A. and Arnold, F.: Sulfuric acid cluster ion formation by jet engines: Implications for sulfuric acid formation and nucleation, Proc. Intern. Scientific Coll.: On impact from aircraft and spacecraft upon the atmosphere, Köln 1994, DLR-Mitt., 94-06, 106-112, 1994.

Haverkamp, H., Wilhelm, S., Sorokin, A., and Arnold, F.: Positive and negative ion measurements in jet air craft engine exhaust: concentrations, sizes and implications for aerosol formation, Atmospheric Environment, submitted, 2003.

Katragkou, E., Kiendler, A., Wilhelm, S., Wolfrom, K. H., and Arnold, F.: Gaseous sulfuric acid measurements in jet aircraft combustor exhaust during the PartEmis experiment, Geophys. Res. Lett., accepted, 2003.

Lefebvre A. H.: Gas turbine combustion, N.Y., McGraw-Hill, 1985.

Matter, D., Mohr, M., Fendel, F., Schmidt-Ott, A., and Burtscher, H.: Multiple wavelength aerosol photoemission by excimer lamps, J. Aerosol Science, 26, 1101-1115, 1995.
ACPD

3, 6001-6018, 2003

\section{Influence of fuel}

sulfur induced stable negative ion formation

A. Sorokin et al.

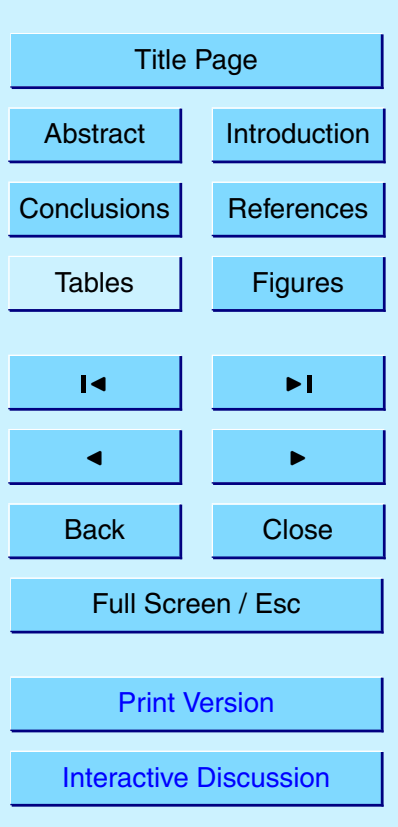

(C) EGU 2003 
Möhler, O., Reiner, T., and Arnold, F.: The formation of $\mathrm{SO}_{5}^{-}$by gas phase ion-molecule reactions, J. Chem. Phys., 97, 8233-8239, 1992.

Petzold, A., Ström, J., Schröder, F.P., and Kärcher, B.: Carbonaceous aerosol in jet engine ACPD exhaust: emission characteristics and implications for heterogeneous chemical reactions, Atmos. Env., 33, 2689-2698, 1999.

Sorokin, A. and Mirabel, P.: Ion recombination in aircraft exhaust plumes, Geophys. Res. Lett., 28, 955-958, 2001.

Sorokin, A., Vancassel, X., and Mirabel, P.: Emissions of ions and charged soot particles by aircraft engines, Atmos. Chem. Phys., 3, 325-334, 2003.

10 Wilson, C. W., Petzold, A., Arnold, F., et al.: Measurement and prediction of emissions of aerosols and gaseous precursors from gas turbine engines (PartEmis): An experimental overview, Aerospace Science and Technology, accepted, 2003.

Yu, F. and Turco, R. P.: The formation and evolution of aerosols in stratospheric aircraft plumes: Numerical simulations and comparison with observations, J. Geophys. Res., 103, 2591525934, 1998.

3, 6001-6018, 2003

Influence of fuel sulfur induced stable negative ion formation

A. Sorokin et al.

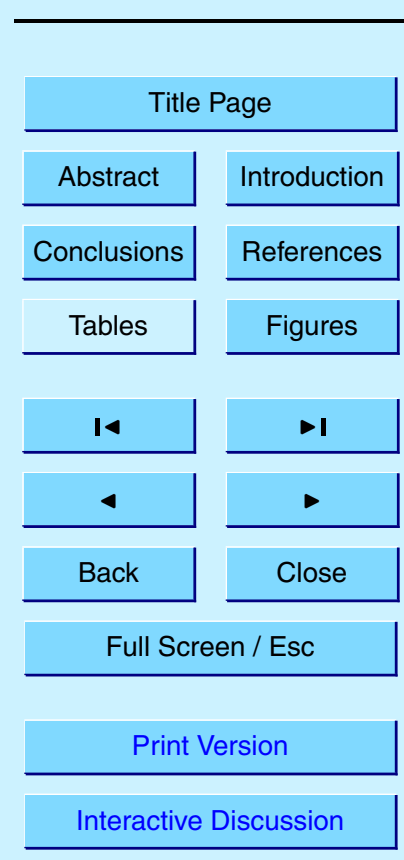




\section{ACPD}

3, 6001-6018, 2003

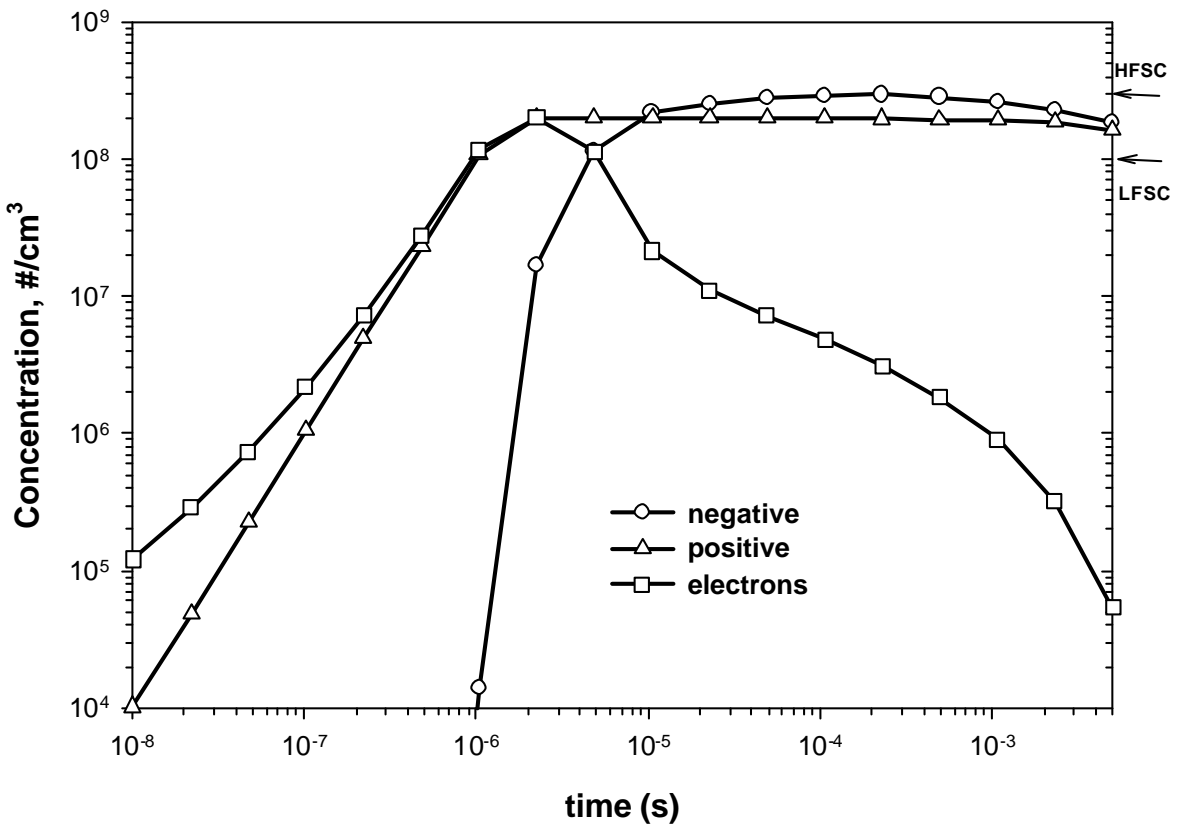

Influence of fuel sulfur induced stable negative ion formation

A. Sorokin et al.

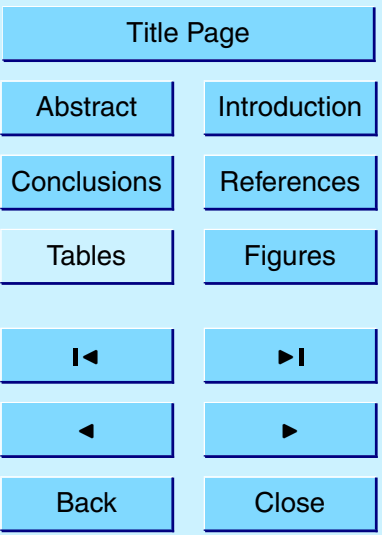

Full Screen / Esc

different values of the electron detachment efficiency $f_{d e t}=0.001$ (a), 0.01 (b) and 0.1 (c). Also shown for comparison are the experimental data.

Print Version

Interactive Discussion

(C) EGU 2003 


\section{ACPD}

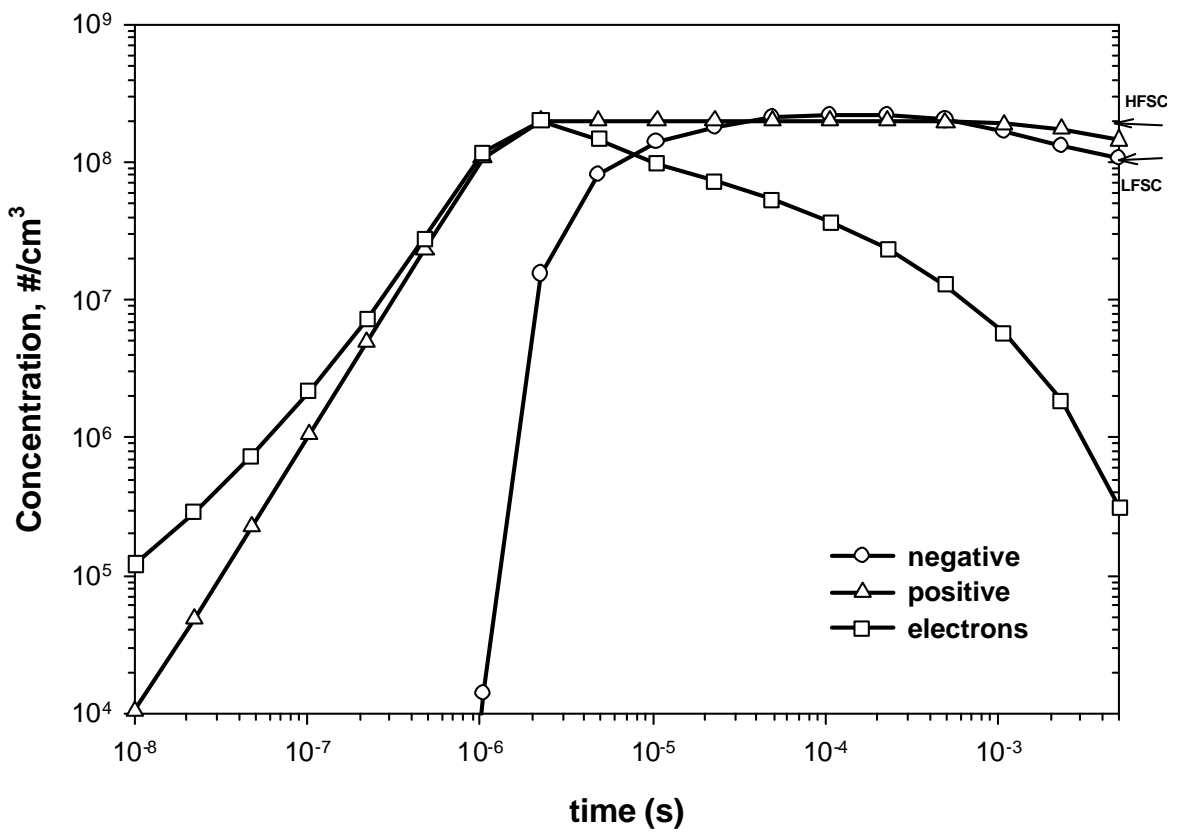

3, 6001-6018, 2003

Influence of fuel sulfur induced stable negative ion formation

A. Sorokin et al.

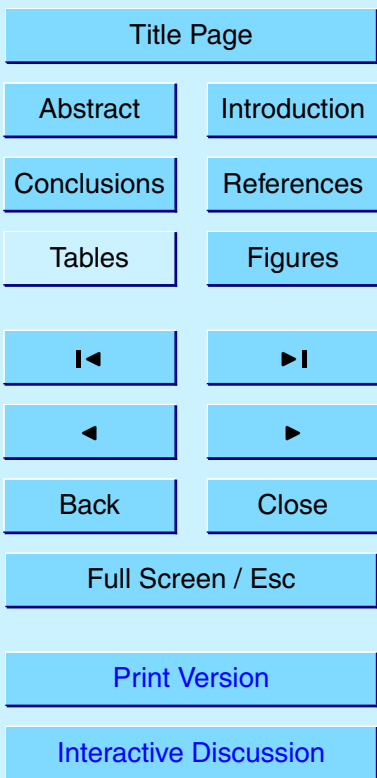

(C) EGU 2003 


\section{ACPD}

3, 6001-6018, 2003

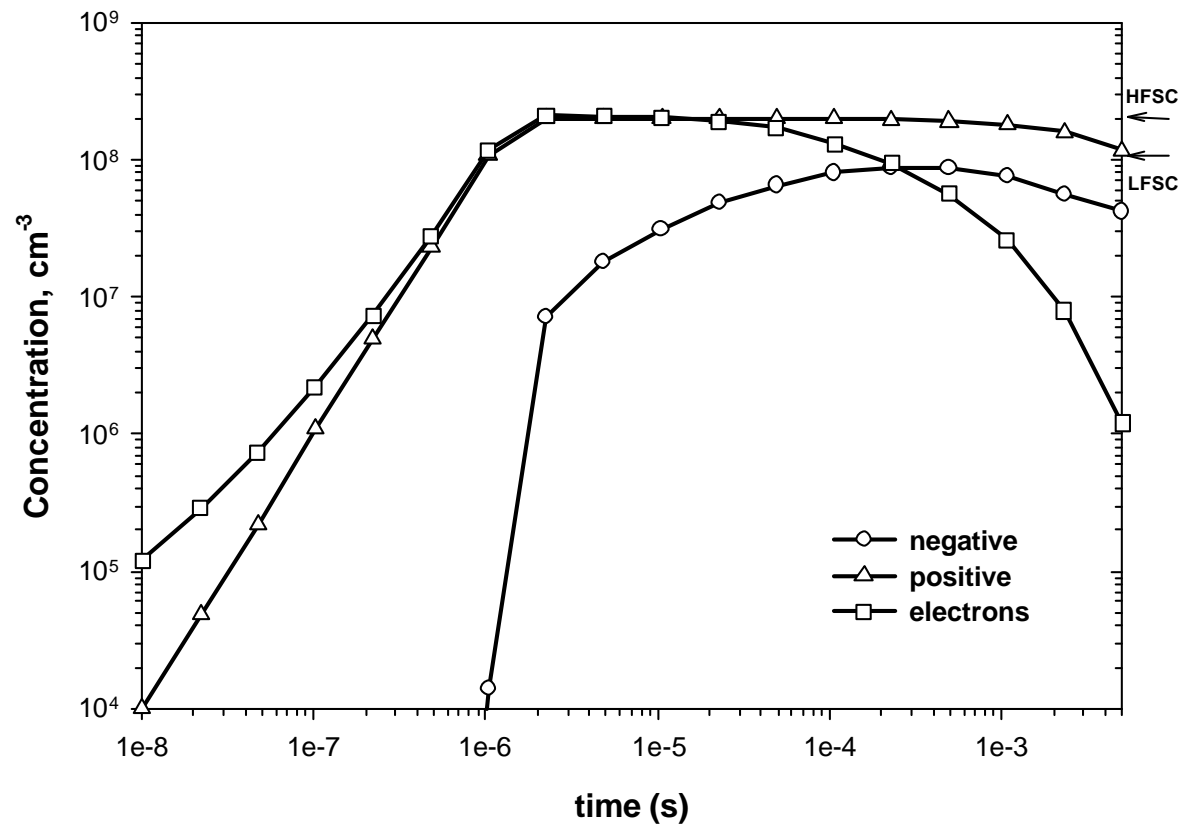

Influence of fuel sulfur induced stable negative ion formation

A. Sorokin et al.

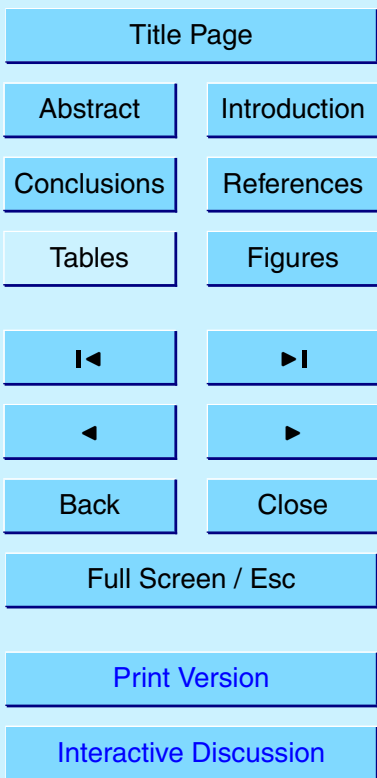

(C) EGU 2003 


\section{ACPD}

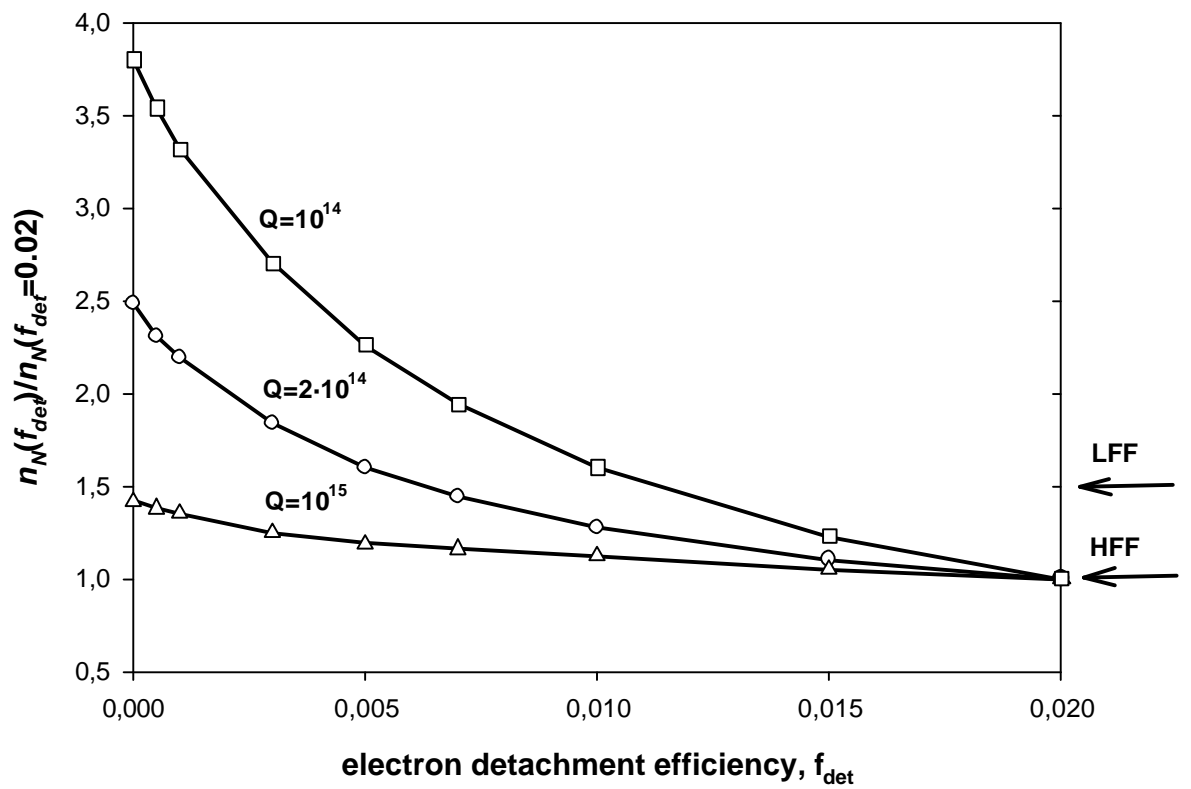

$3,6001-6018,2003$

Influence of fuel sulfur induced stable negative ion formation

A. Sorokin et al.

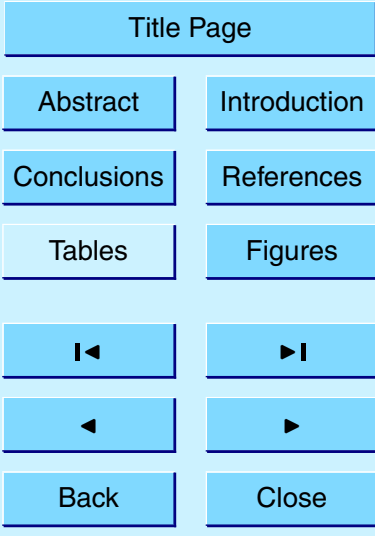

Full Screen / Esc the electron detachment efficiency for different values of the chemiion formation rate $Q$ in the flame zone. Also shown for comparison are the experimental data.

Print Version

Interactive Discussion

(C) EGU 2003 


\section{ACPD}

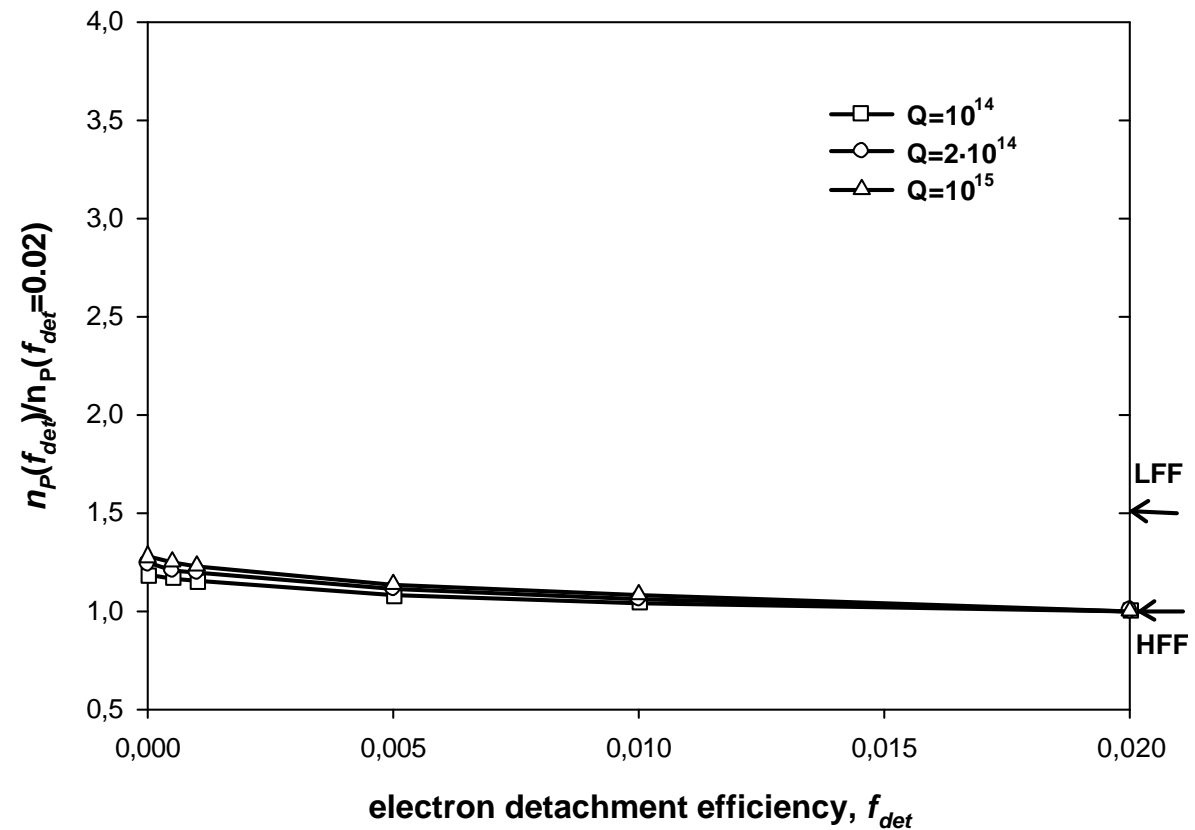

3, 6001-6018, 2003

Influence of fuel sulfur induced stable negative ion formation

A. Sorokin et al.

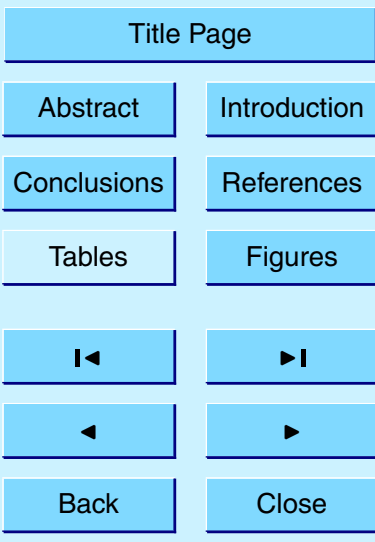

Full Screen / Esc

Fig. 2. (b) Continued.

Print Version

Interactive Discussion

(C) EGU 2003 


\section{ACPD}

$3,6001-6018,2003$

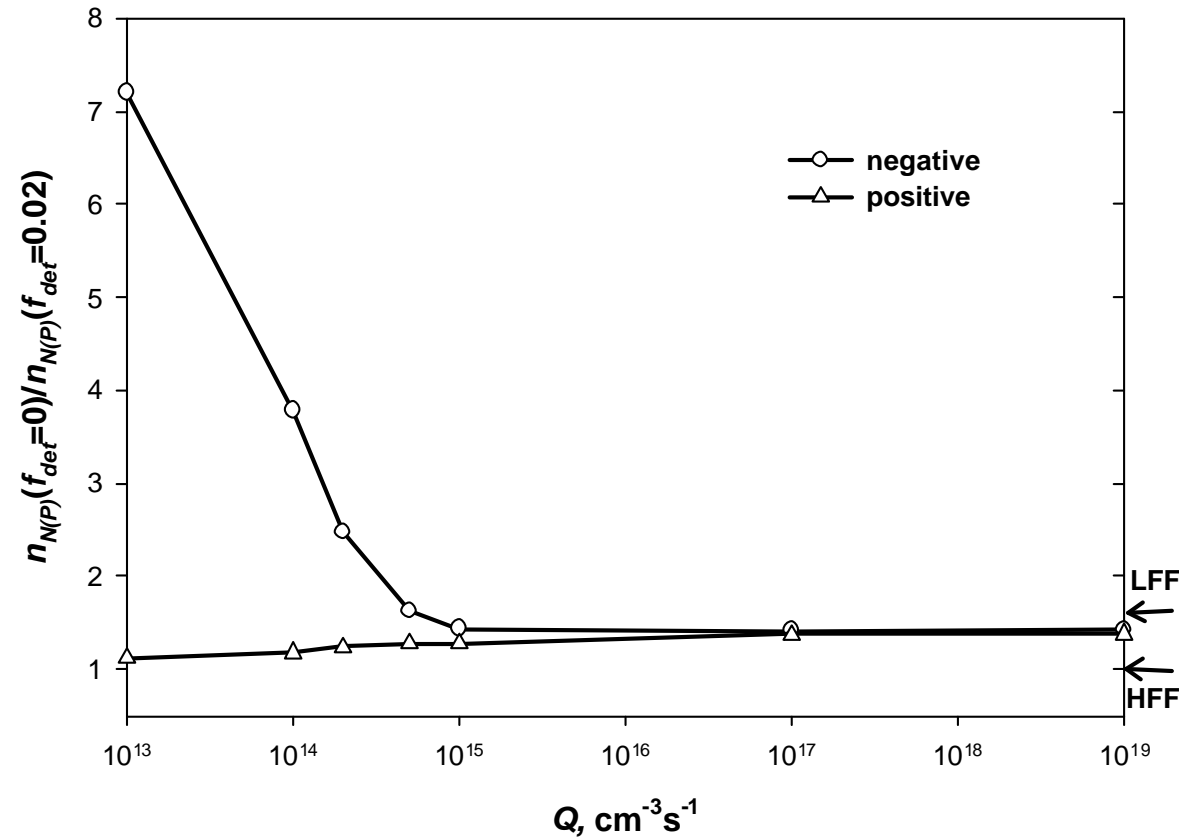

Influence of fuel sulfur induced stable negative ion formation

A. Sorokin et al.

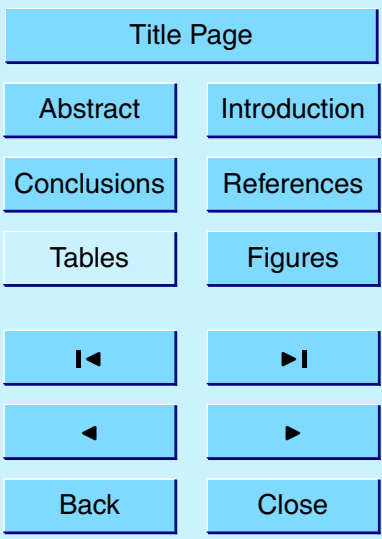

Full Screen / Esc

Fig. 3. Ratio of the concentrations of positive and negative ions at the combustor exit for two values of the electron detachment coefficient $f_{\text {det }}=0$ and 0.02 versus the chemiion formation rate $Q$. Also shown for comparison are the experimental data.

Print Version

Interactive Discussion

(C) EGU 2003 


\section{ACPD}

3, 6001-6018, 2003

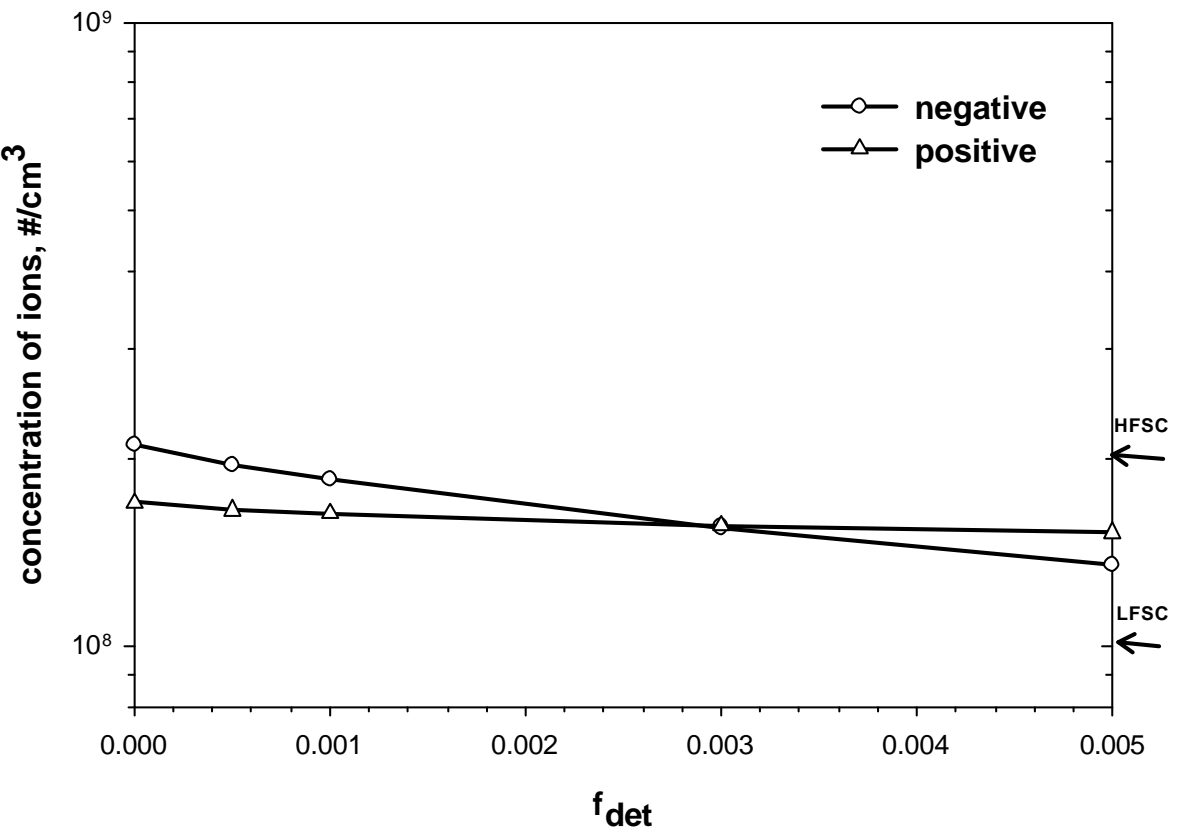

Influence of fuel sulfur induced stable negative ion formation

A. Sorokin et al.

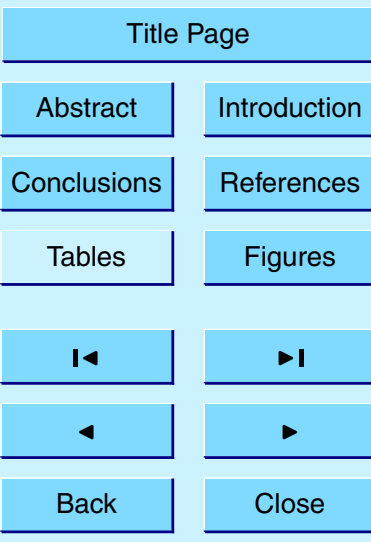

Full Screen / Esc

detachment efficiency for $Q=2 \times 10^{14} \mathrm{~cm}^{-3} \mathrm{~s}^{-1}$. Also shown for comparison are the experimental data.

Print Version

Interactive Discussion

(C) EGU 2003 